\title{
Metabolic responses to isoenergetic meals containing different proportions of carbohydrate and fat
}

\author{
BY HELENA A. WHITLEY ${ }^{1}$, SANDY M. HUMPHREYS ${ }^{1}$, JASWINDER S. SAMRA ${ }^{1}$, \\ IAIN T. CAMPBELL ${ }^{2}$, DONALD P. M. MACLAREN ${ }^{3}$, TOM REILLY ${ }^{3}$ \\ AND KEITH N. FRAYN ${ }^{1}$ \\ 'Oxford Lipid Metabolism Group, Radcliffe Infirmary, Woodstock Road, Oxford OX2 6HE \\ ${ }^{2}$ University Department of Anaesthesia, Withington Hospital, Nell Lane, Manchester M20 8LR \\ ${ }^{3}$ Centre for Sport and Exercise Sciences, Liverpool John Moores University, Mountford Building, \\ Byrom Street, Liverpool L3 $3 A F$
}

(Received 2 August 1996 - Revised 2 January 1997 - Accepted 16 January 1997)

\begin{abstract}
The purpose of the present study was to investigate the interrelationship between carbohydrate and fat metabolism at rest after isoenergetic meals of varying proportions of carbohydrate and fat. Eight physically-active subjects (BMI 18.1-23.4 kg/m $\mathrm{m}^{2}$ ) were studied at rest on three occasions after an overnight fast. In a balanced design they were given meals containing carbohydrate, protein and fat in the following amounts respectively $(\mathrm{g} / 70 \mathrm{~kg}$ body weight): meal $1121,16,48$; meal $270,16,70$; meal $350,14,80$. All meals were isoenergetic, containing $4 \cdot 0 \mathrm{MJ} / 70 \mathrm{~kg}$ body weight, and were of similar appearance. In addition, on a fourth occasion five of the eight subjects consumed meal 4 ( $\mathrm{g} / 70 \mathrm{~kg}$ body weight): carbohydrate 0 , protein 0 , fat 108 . Blood samples were taken before eating the meal and at intervals following the meal to determine metabolic and hormonal responses. Energy expenditure and substrate oxidation were measured by indirect calorimetry and balance was calculated over the $5 \mathrm{~h}$ postprandial period. The incremental areas under the time curves for fat oxidation were greatest after meals 3 and $4(P<0 \cdot 05)$, whereas incremental areas under the carbohydrate oxidation $v$. time curves were relatively reduced after these two meals $(P<0 \cdot 05)$. This was accompanied by lesser suppression of plasma non-esterified fatty acid concentrations $(P<0 \cdot 001)$ and reduced plasma insulin concentrations $(P<0 \cdot 001)$ following these meals. Energy balance was almost identical after the three isoenergetic meals. In contrast, there was an inverse relationship between carbohydrate and fat balance following these meals, with carbohydrate balance decreasing as carbohydrate intake decreased and fat balance increasing as fat intake increased. We conclude that there is a close interrelationship between carbohydrate and fat metabolism following isoenergetic meals in resting subjects.
\end{abstract}

Isoenergetic meals: Substrate balance: Substrate oxidation

It is well established that carbohydrate and fat metabolism are interrelated (Randle et al. 1963), although the mechanisms regulating their relative oxidation rates are poorly understood. In human subjects the ability to adjust fat oxidation to fat intake appears to be less effective than the ability to adjust carbohydrate and protein oxidation to carbohydrate and protein intake respectively (Abbott et al. 1988). Flatt et al. (1985) reported that addition of $50 \mathrm{~g}$ fat to a mainly-carbohydrate breakfast caused no alteration in the oxidation of individual macronutrients over the subsequent $9 \mathrm{~h}$, implying that all the additional fat had been stored. Similar findings have been reported from other studies over periods of up to $24 \mathrm{~h}$ (Schutz et al. 1989; Bennett et al. 1992). In the study of Griffiths et al. (1994), addition of $80 \mathrm{~g}$ fat to a meal containing $80 \mathrm{~g}$ carbohydrate led to the subsequent oxidation of only $10 \mathrm{~g}$ additional fat, and the storage of $70 \mathrm{~g}$. These studies compared carbohydrate 
and fat oxidation following meals with differing energy contents, such that energy intake increased in relation to the fat added to the meal. Surplus energy in the form of fat would lead to a positive energy balance, and energy balance is closely correlated with fat balance even over short periods (Abbott et al. 1988; Schutz et al. 1989). When subjects are in constant energy balance, variations in fat and carbohydrate intake in the diet lead to changes in their relative oxidation rates (Verboeket-van de Venne et al. 1994). The purpose of the present study was to investigate the interrelationship between carbohydrate and fat metabolism at rest after consuming single isoenergetic meals containing varying proportions of carbohydrate and fat.

\section{MATERIALS AND METHODS}

\section{Subjects}

Eight physically-active female subjects participated in the study. Their physical characteristics are shown in Table 1 . Subjects were given both verbal and written instructions outlining the experimental procedure, and written informed consent was obtained. The study was approved by the Central Oxford Research Ethics Committee.

\section{Experimental design}

Subjects attended for three studies in a random order, with five subjects attending on a fourth occasion for a fat-only meal. All subjects were studied in the follicular phase of the menstrual cycle in order to minimize the effects of hormonal perturbations. One calendar month was allowed to elapse between each study. Subjects were asked to consume a virtually-fat-free meal ( $<1 \mathrm{~g}$ fat) the evening before the study, and were given instructions on how to achieve this. They were asked to refrain from caffeinated drinks $2 \mathrm{~d}$ before each study. In addition, subjects attended on a further occasion and performed a submaximal cycle ergometer test to predict maximal $\mathrm{O}_{2}$ uptake $\left(\dot{V}_{\mathrm{O}_{2} \text { max }}\right.$; Åstrand \& Ryhming, 1954). Height, body mass and percentage body fat estimated from skinfold thicknesses (Durnin \& Womersley, 1974) were also measured at this visit.

\section{Protocol}

Subjects attended the laboratory after an overnight fast. A cannula was placed anterogradely in a vein draining a hand which was warmed throughout the study in a heated pad to provide arterialized blood (McGuire et al. 1976). The cannula was kept patent with slow saline $(9 \mathrm{~g} \mathrm{NaCl} / \mathrm{l})$ infusion. Indirect calorimetry was performed using a

Table 1. Physical characteristics of subjects

\begin{tabular}{lcc}
\hline \hline Variable & Mean & Range \\
\hline Age (years) & 28.3 & $20-41$ \\
Height (m) & 1.70 & $1.64-1.79$ \\
Body mass $(\mathrm{kg})$ & 61.9 & $53-68$ \\
BMI $\left(\mathrm{kg} / \mathrm{m}^{2}\right)$ & 21.4 & $18.1-23.4$ \\
Percentage body fat & 23.4 & $19.0-27.8$ \\
$\dot{V}_{\mathrm{O}_{2} \max }(\mathrm{ml} / \mathrm{kg}$ per min) & 53.6 & $47.0-59.3$ \\
Plasma cholesterol (mmol/l) & 4.5 & $3.6-5.6$ \\
HDL-cholesterol (mmol/l) & 1.58 & $1.34-1.79$ \\
\hline
\end{tabular}


Table 2. Composition of test meals ${ }^{*}$

\begin{tabular}{|c|c|c|c|c|c|}
\hline \multirow[t]{2}{*}{ Test meal... } & \multirow[t]{2}{*}{1} & \multirow[t]{2}{*}{2} & \multirow[t]{2}{*}{3} & \multicolumn{2}{|c|}{4} \\
\hline & & & & Intended & $\overline{\text { Actual } \dagger}$ \\
\hline Fat (g) & $48 \cdot 0$ & $70 \cdot 3$ & $80 \cdot 0$ & 108.0 & $70 \cdot 1$ \\
\hline Saturated fat $(\mathrm{mg} / \mathrm{g})$ & 380 & 370 & 380 & 190 & 190 \\
\hline$\%$ Energy as fat & 44.5 & $65 \cdot 2$ & 73.9 & 99.8 & 99.7 \\
\hline Carbohydrate (g) & $121 \cdot 1$ & 70.3 & $50 \cdot 0$ & 0.5 & 0.5 \\
\hline Simple sugars $(\mathrm{mg} / \mathrm{g})$ & 496 & 506 & 510 & 1000 & 1000 \\
\hline$\%$ Energy as carbohydrate & 48.6 & 28.2 & $20 \cdot 0$ & 0.2 & 0.3 \\
\hline Protein $(\mathrm{g})$ & 16.3 & 15.6 & 14.4 & Negligible & Negligible \\
\hline$\%$ Energy as protein & 6.9 & 6.6 & $6 \cdot 1$ & Negligible & Negligible \\
\hline Total energy $(\mathrm{kJ})$ & 3990 & 3989 & 4002 & 4004 & 2602 \\
\hline
\end{tabular}

* All meals are based on a $70 \mathrm{~kg}$ reference person and were adjusted for each individual according to body weight. Subjects were given a cup of decaffeinated tea or coffee and one glass of water with each meal.

$\dagger$ Subjects found difficulty in consuming all meal 4 , so an average of the 'actual' amount consumed by five subjects is shown.

Delta-trac system (S. W. Vickers, Sidcup, Kent) in the basal state and for a $30 \mathrm{~min}$ period in each hour following the meal. Such intermittent measurements have been shown to give more reliable results in the postprandial period than continuous measurement (Piers et al. 1992). Measurements were not made, however, during the first hour following the meal as some subjects felt slightly nauseous at that time. It does not seem probable that the lack of data during the first hour will have affected the overall pattern of results, since in other studies with a complete time-course for the postprandial period only a small proportion of the incremental (I) areas under curves (AUC) for respiratory exchange ratio (RER) or substrate oxidation were observed in the first hour (Griffiths et al. 1994).

Two baseline blood samples were drawn (separated by $20 \mathrm{~min}$ ) before the subject ate one of four test meals. The composition of the four meals is displayed in Table 2. The constituents for meals 1, 2 and 3 were chosen to typify a breakfast cereal, comprising oats, coconut, almonds, raisins, honey, sunflower oil, banana, double cream and milk, and were selected to resemble each other both in appearance and palatability. They had similar proportions of simple sugars relative to total carbohydrate, and similar saturated : unsaturated fatty acid values. In contrast, meal 4 was in the form of a long-chain triacylglycerol (TAG) emulsion drink (Calogen; Scientific Hospital Supplies Group UK Ltd, Liverpool), which was not isoenergetic with the other three meals as subjects found difficulty in consuming this meal. Further blood samples were taken at 15 and $30 \mathrm{~min}$ intervals for a period of $5 \mathrm{~h}$.

\section{Analytical methods}

Blood samples were taken into heparinized syringes (Monovette; Sarstedt, Leicester). A portion was used immediately for measurement of blood glucose concentration in duplicate (Hemocue B-glucose photometer; Hemocue Ltd, Sheffield). From the remaining blood, plasma was separated rapidly at $4^{\circ}$. A portion of the plasma was used for preparation of a chylomicron-rich fraction as follows. Duplicate portions of plasma $(0.5 \mathrm{ml})$ were gently pipetted under $0.3 \mathrm{ml}$ of a solution with a density of $1.006 \mathrm{~kg} / \mathrm{l}$ in a microcentrifuge tube, and the tube topped up with the solution of density $1.006 \mathrm{~kg} / \mathrm{l}$. The tubes were centrifuged at $12000 \mathrm{~g}$ for $2 \mathrm{~h}$ and the chylomicron-rich fraction harvested by aspiration. The duplicate preparations from each sample were then pooled and weighed for subsequent determination of chylomicron TAG concentration. Additional portions of plasma were 

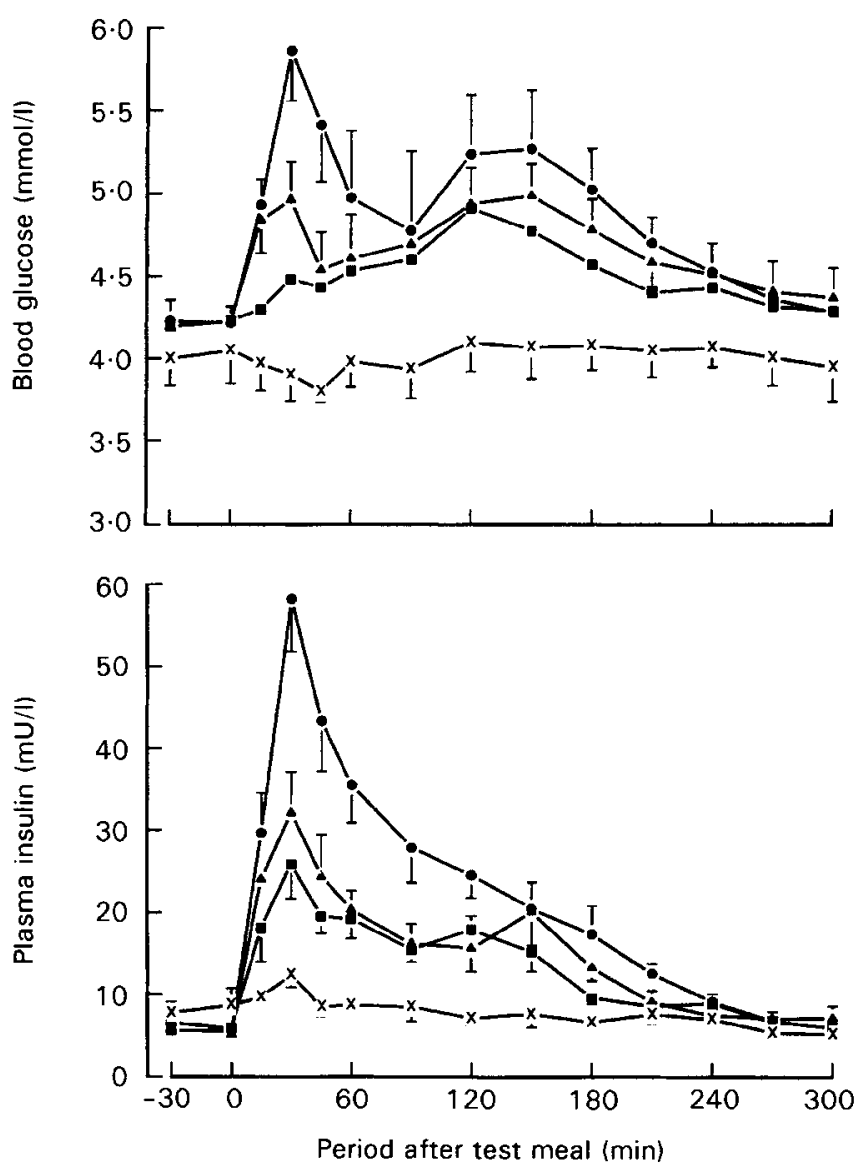

Fig. 1. Blood glucose concentrations and plasma insulin concentrations of physically-active subjects at rest before and after four test meals containing varying proportions of fat and carbohydrate: $(\boldsymbol{O})$, meal $1 ;(\boldsymbol{\Delta})$, meal $2 ;(\boldsymbol{\square})$, meal $3 ;(\mathbf{X})$, meal 4 . Values are means with their standard errors represented by vertical bars for eight subjects for meals 1,2 and 3 and for five subjects for meal 4. Repeated-measures ANOVA for glucose for meals 1-3 showed significant effects of time $(P<0.001)$ and interaction between time and meal type $(P=0.001)$, and for meals $1-4$ significant effects of time $(P=0.008)$, of meal type $(P=0.001)$ and interaction between time and meal type $(P=0.007)$. For plasma insulin for meals $1-3$ and for meals $1-4$ there were significant effects of time, of meal type and interaction between time and meal type (all $P<0.001$ ). For details of subjects and test meals, see Tables 1 and 2 ; for details of procedures, see pp. 16-19.

frozen for subsequent determination of plasma non-esterified fatty acid (NEFA) and TAG concentrations by enzymic methods using an IL Monarch centrifugal analyser (Instrumentation Laboratory, Warrington, Ches.), and of plasma insulin by doubleantibody radioimmunoassay (kit from Pharmacia, Milton Keynes, Bucks.). Additionally, in one fasting sample, plasma cholesterol was measured by an enzymic method (kit from Pointe Scientific; Cozart Bioscience, Abingdon, Berks.) and HDL-cholesterol after heparin-Mn precipitation (Warnick \& Albers, 1978).

\section{Statistical procedures}

The data from the indirect calorimetry were used to calculate fat and carbohydrate oxidation and energy expenditure following each test meal. As $\mathrm{N}$ excretion was not 
Table 3. Incremental areas under the curve (IAUC) $\ddagger$ for plasma and blood metabolite concentrations v. time for physically-active subjects at rest after four test meals containing varying proportions of fat and carbohydrate§

(Mean values with their standard errors for eight subjects for meals 1,2 and 3 and for five subjects for meal 4)

\begin{tabular}{|c|c|c|c|c|c|c|c|c|c|c|}
\hline \multirow[b]{2}{*}{ Test meal } & \multicolumn{2}{|c|}{$\begin{array}{l}\text { Blood glucose } \\
(\mathrm{mmol} / \mathrm{l})\end{array}$} & \multicolumn{2}{|c|}{$\begin{array}{c}\text { Insulin } \\
(\mathrm{mU} / \mathrm{l})\end{array}$} & \multicolumn{2}{|c|}{$\begin{array}{l}\text { chylomicron } \\
\text { TAG }(\mu \mathrm{mol} / \mathrm{l})\end{array}$} & \multicolumn{2}{|c|}{$\begin{array}{c}\mathrm{TAG} \\
(\mu \mathrm{mol} / \mathrm{l})\end{array}$} & \multicolumn{2}{|c|}{$\begin{array}{l}\text { NEFA } \\
(\mu \mathrm{mol} / 1)\end{array}$} \\
\hline & Mean & SEM & Mean & SEM & Mean & SEM & Mean & SEM & Mean & SEM \\
\hline 1 & 0.66 & 0.18 & $16 \cdot 0^{* * *}$ & 1.63 & $162 \cdot 2$ & 27.7 & $237 \cdot 3$ & $43 \cdot 0$ & -234.8 & $70 \cdot 4$ \\
\hline 2 & 0.46 & 0.07 & 9.35 & 0.90 & 148.4 & 21.8 & $262 \cdot 3$ & $45 \cdot 0$ & -163.5 & $26 \cdot 2$ \\
\hline 3 & 0.31 & 0.04 & 7.04 & 0.45 & 213.4 & $40 \cdot 8$ & 270.9 & 61.9 & $-50 \cdot 0$ & $52 \cdot 3$ \\
\hline 4 & 0.01 & 0.06 & $-0.61 \dagger+\dagger$ & 1.17 & $235 \cdot 8$ & $34 \cdot 1$ & $556 \cdot 3$ & 134.0 & $110.8+\dagger$ & 45.5 \\
\hline
\end{tabular}

TAG, triacylglycerol; NEFA, non-esterified fatty acids.

Mean values were significantly different between meals 1,2 and $3: * * * P<0.001$.

Mean values were significantly different between the four meals: $\dagger+P<0 \cdot 01, \dagger+\dagger P<0.001$.

$\ddagger$ IAUC were divided by the time baseline to represent the average change from baseline over the $5 \mathrm{~h}$ postprandial period.

$\S$ For details of subjects and test meals, see Tables 1 and 2 ; for details of procedures, see pp. 16-19.

measured in the present study, values were taken from similar studies by Flatt et al. (1985). The value used was $0.11 \mathrm{mg} \mathrm{N} / \mathrm{kg}$ body weight per h, equivalent to $3 \mathrm{~g}$ protein oxidation per $\mathrm{h}$ for a $72 \mathrm{~kg}$ person.

For statistical analyses, changes in the metabolic responses to the meals with time were assessed using ANOVA for repeated measures. Comparisons were made separately for meals 1-3 (which were isoenergetic) and for meals 1-4. In addition, postprandial measurements were assessed as IAUC and analysed using ANOVA. The IAUC were calculated as the total AUC minus the basal value, extrapolated over the $5 \mathrm{~h}$ postprandial period. This value was then divided by the total time period to give an average change from baseline for the $5 \mathrm{~h}$ postprandial period. For all statistical analyses, a level of $P<0.05$ was considered to be statistically significant. For values attaining this criterion, post hoc analysis was performed using Tukey's honestly significant difference test, to elucidate which meals were significantly different.

\section{RESULTS}

\section{Blood glucose and plasma insulin concentrations}

The blood glucose concentration increased above pre-meal values during the first $30 \mathrm{~min}$ after meal 1 (Fig. 1). This initial peak was less pronounced after meals 2 and 3, but followed a similar pattern, reaching a second peak at $2 \mathrm{~h}$, followed by a gradual decline to basal levels towards the end of the study. In contrast, after meal 4 the blood glucose concentration remained almost constant throughout the postprandial period. Similarly, plasma insulin rose during the first $30 \mathrm{~min}$ following meal 1 and then declined rapidly to basal levels towards the end of the postprandial period (Fig. 1). This pattern was observed to a lesser extent after meals 2 and 3, whereas with meal 4 there was no change from baseline throughout the postprandial period. Statistical analysis showed a significant difference in the IAUC for plasma insulin $v$. time between the four meals (Table 3). Post $h o c$ analysis of the mixed meals revealed that meal 1 differed significantly from meals 2 and 3 respectively, and that meal 4 differed significantly when compared with the other three meals. 


\section{Plasma chylomicron triacylglycerol and plasma triacylglycerol and non-esterified fatty acid concentrations}

The plasma chylomicron TAG concentration was close to zero in the baseline samples, and was elevated above pre-meal concentrations following all meals (Fig. 2). Plasma TAG concentrations followed a similar pattern after meal 4 with prolonged elevation throughout the postprandial period (Fig. 2). In comparison, after the other three meals the plasma TAG concentration behaved almost identically with a gradual rise to a plateau at $3 \mathrm{~h}$ and then a slow fall to baseline values.
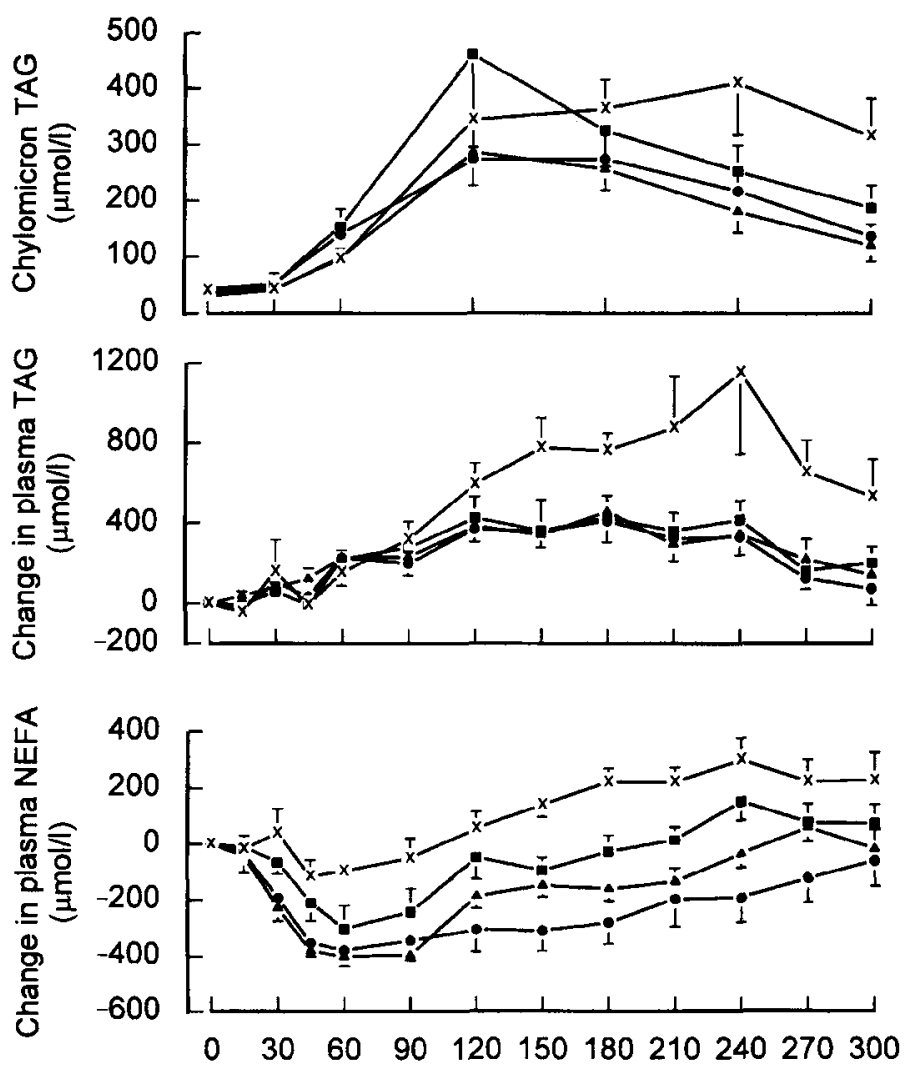

Period after test meal (min)

Fig. 2. Change in plasma chylomicron triacylglycerol (TAG) concentrations, plasma TAG concentrations and plasma non-esterified fatty acid (NEFA) concentrations of physically-active subjects at rest after four test meals containing varying proportions of fat and carbohydrate: $(\boldsymbol{O})$, meal $1 ;(\boldsymbol{\Lambda})$, meal $2 ;(\boldsymbol{D})$, meal $3 ;(\boldsymbol{X})$, meal 4 . Values are means with their standard errors represented by vertical bars for eight subjects for meals 1,2 and 3 and for five subjects for meal 4. Repeated-measures ANOVA for chylomicron TAG for meals 1-3 showed significant effects of time $(P<0.001)$, and for meals $1-4$ significant effects of time $(P<0.001)$ and interaction between time and meal type $(P=0.003)$. For plasma TAG for meals $1-3$ there were significant effects of time $(P<0.001)$, and for meals $1-4$ significant effects of time $(P<0.001)$ and interaction between time and meal type $(P=0.034)$. For plasma NEFA for meals 1-3 there were significant effects of time, of meal type and interaction between time and meal type (all $P<0.001$ ), and the same findings were obtained for meals $1-4$ (time, $P<0.001$; meal type, $P=0.002$; interaction, $P<0.001)$. 
Table 4. Incremental areas under the curve (IAUC) $\ddagger$ for substrate oxidation and energy expenditure v. time for physically-active subjects at rest after four test meals containing varying proportions of fat and carbohydrate§

(Mean values with their standard errors for eight subjects for meals 1, 2 and 3 and for five subjects for meal 4)

\begin{tabular}{|c|c|c|c|c|c|c|}
\hline \multirow[b]{2}{*}{ Test meal } & \multicolumn{2}{|c|}{$\begin{array}{l}\text { Carbohydrate oxidation } \\
(\mathrm{mg} / \mathrm{kg} \text { per } \mathrm{h})\end{array}$} & \multicolumn{2}{|c|}{$\begin{array}{l}\text { Fat oxidation } \\
(\mathrm{mg} / \mathrm{kg} \text { per } \mathrm{h})\end{array}$} & \multicolumn{2}{|c|}{$\begin{array}{l}\text { Energy expenditure } \\
(\mathrm{kJ} / \mathrm{kg} \text { per } \mathrm{h})\end{array}$} \\
\hline & Mean & SEM & Mean & SEM & Mean & SEM \\
\hline 1 & $66 \cdot 2^{*}$ & 10.7 & $-14.0 *$ & 4.59 & 0.49 & 0.08 \\
\hline 2 & 27.2 & 8.40 & -3.57 & 3.56 & 0.29 & 0.11 \\
\hline 3 & 20.0 & $15 \cdot 4$ & -0.11 & 4.79 & 0.30 & 0.06 \\
\hline 4 & $-21 \cdot 3+\dagger$ & 18.2 & $8.48 \dagger$ & 8.65 & $0.00 \dagger$ & 0.07 \\
\hline
\end{tabular}

Mean values were significantly different between meals 1,2 and $3:{ }^{*} P<0.05$.

Mean values were significantly different between the four meals: $\dagger P<0.05, \dagger \dagger P<0.01$.

¥IAUC were divided by the time baseline to represent the average change from baseline over the $5 \mathrm{~h}$ postprandial period.

$\S$ For details of subjects and test meals, see Tables 1 and 2 ; for details of procedures, see pp. 16-19.

Plasma NEFA concentrations decreased below pre-meal values during the first hour following meals 1, 2 and 3 (Fig. 2). The suppression of plasma NEFA concentration continued throughout the postprandial period after meals 1 and 2 , gradually rising to approach baseline values at $5 \mathrm{~h}$ after the meal. This suppression of NEFA concentration was less following meals 3 and 4, with NEFA concentrations increasing above baseline level by $3.5 \mathrm{~h}$, whereas after meal 1 NEFA concentrations remained below baseline throughout the study. Consequently, there was a significant difference in the IAUC for NEFA concentration $v$. time between the four meals (Table 3), with post hoc analysis revealing meals 1 and 2 to be significantly different from meal 4 .

\section{Indirect calorimetry}

The RER increased above pre-meal values during the first hour after meals 1, 2 and 3, reflecting an increase in the proportion of carbohydrate oxidized (Fig. 3), with a gradual decline to basal levels towards the end of the study. In contrast, after meal 4 the RER decreased, reflecting an increase in fat oxidation. Statistical analysis showed significant differences in IAUC for carbohydrate oxidation $v$. time and fat oxidation $v$. time between the four meals (Table 4). Post hoc analysis revealed that the increase in carbohydrate oxidation after meal 1 was significantly greater than that after meals 2,3 and 4 . Similarly, the decrease in fat oxidation after meal 1 was significantly greater than that after meals 3 and 4.

Energy expenditure rose following meals 1, 2 and 3 (Fig. 3). In contrast, energy expenditure did not change from baseline following meal 4. Consequently, the IAUC for energy expenditure $v$. time was significantly greater following meals 1,2 and 3 when compared with meal 4 (Table 4).

Energy balance, the difference between the total energy intake and the total energy expended during the postprandial period, was identical after meals 1,2 and 3, but lower after meal 4 (but this meal was not isoenergetic with the other three meals; Fig. 4).

Net substrate balance was calculated as the difference between the amount of fat or carbohydrate ingested and the total amount oxidized during the $5 \mathrm{~h}$ postprandial period. The net carbohydrate balance was positive for both meals 1 and 2, whereas after meal 3 


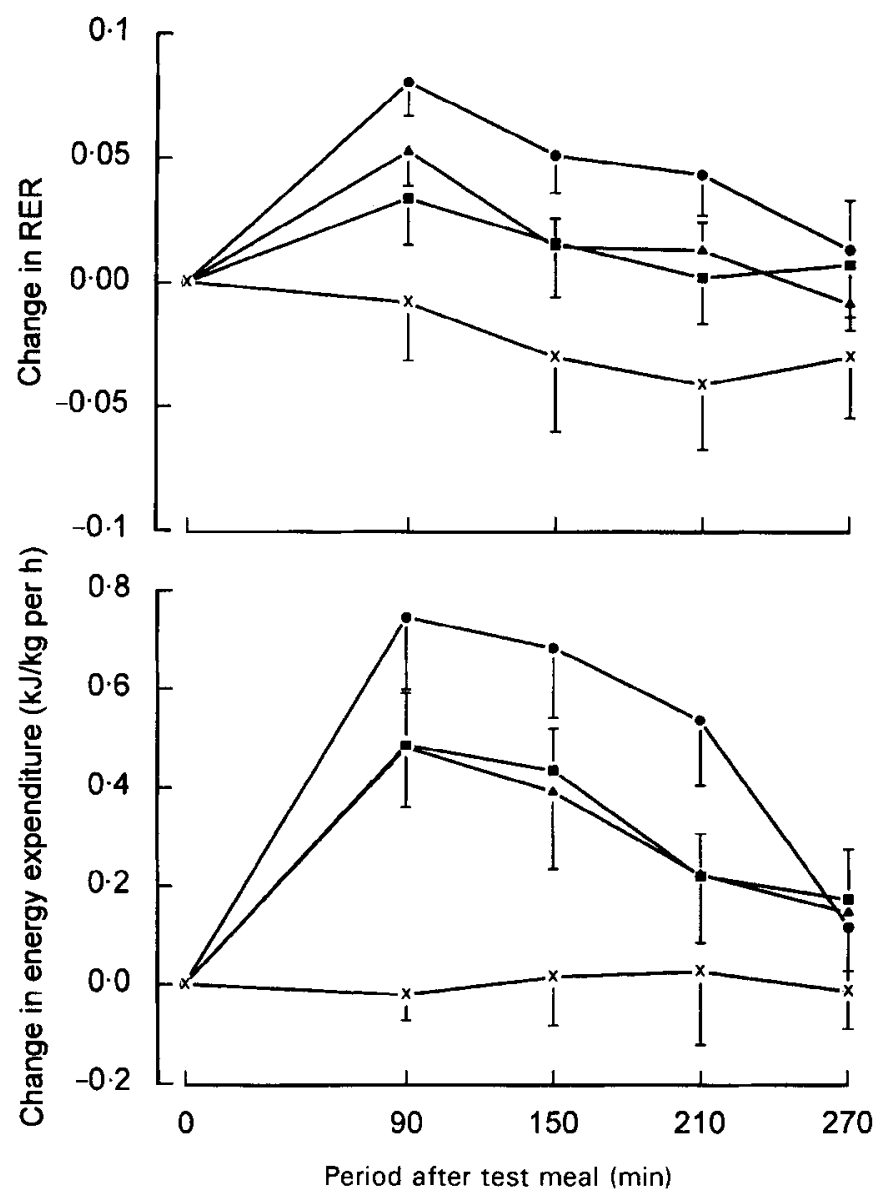

Fig. 3. Change in respiratory exchange ratio (RER) and energy expenditure of physically-active subjects at rest after four test meals containing varying proportions of fat and carbohydrate: $(\boldsymbol{O})$, meal $1 ;(\boldsymbol{\Delta})$, meal 2 ; ( $\square$ ), meal 3; (X), meal 4. Values are means with standard errors represented by vertical bars for eight subjects for meals 1,2 and 3 and for five subjects for meal 4. For details of subjects and test meals, see Tables 1 and 2; for details of procedures, see pp. 16-19.

there was no change, with a negative carbohydrate balance following meal 4 (Fig. 4). In contrast, net fat balance was positive after all four meals, the body's fat stores increasing in parallel with the amount of fat in the meal (Fig. 4). Post hoc analysis showed significant differences in carbohydrate balance between all four meals. Paired meal comparisons of fat balance following the four meals displayed significant differences between meals 1, 2 and 3 only.

\section{DISCUSSION}

\section{Blood and plasma metabolite concentrations}

In the present study the addition of carbohydrate to a fat meal progressively increased postprandial glucose concentrations. This is in accordance with previous studies which observed a progressive increase in plasma glucose concentrations with increasing glucose 


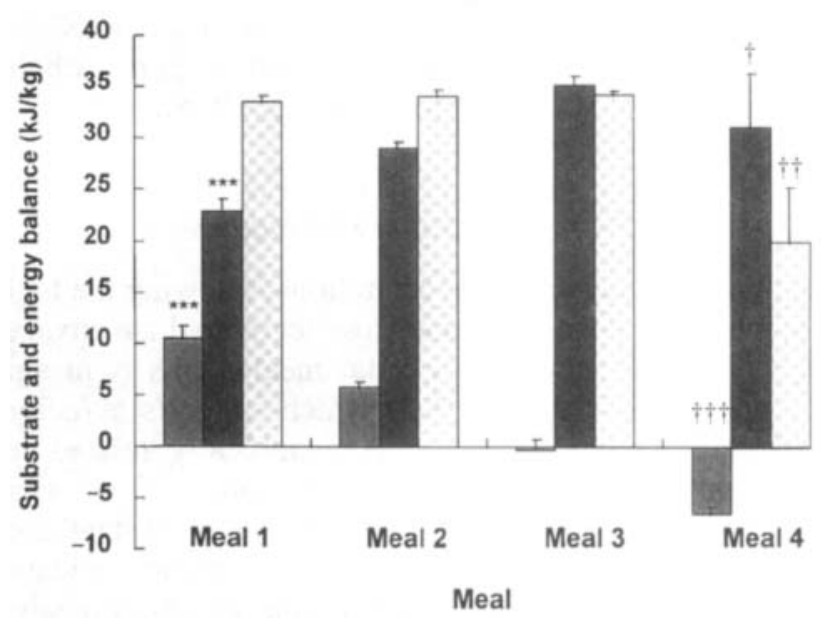

Fig. 4. Energy and substrate balance (expressed per kg body weight) of physically-active subjects at rest during $5 \mathrm{~h}$ after four test meals containing varying proportions of fat and carbohydrate: 橉, carbohydrate balance; $\square$, fat balance; $\square$, energy balance. Values are means with standard errors represented by vertical bars for eight subjects for meals 1,2 and 3 and for five subjects for meal 4 . Mean values were significantly different between meals $1-3: * * * P<0 \cdot 001$. Mean values were significantly different between meals $1-4: \dagger P<0.05,+\dagger P<0.01, \dagger+\dagger P<0.001$.

loads (Castro et al. 1970; Bratusch-Marrain et al. 1980). Similarly, plasma insulin concentrations increased in a parallel fashion.

In contrast, postprandial plasma TAG concentrations did not increase with increasing proportions of dietary fat. It might have been expected that the enhanced secretion of insulin following meal 1 would activate the enzyme lipoprotein lipase (EC 3.1.1.34; LPL) in adipose tissue (Lithell et al. 1978; Eckel, 1989). This enzyme regulates the removal of chylomicron TAG from the circulation at the capillary endothelium of adipose tissue. In this manner, insulin activation of LPL serves to increase TAG uptake and storage following a single meal. Hence, the increased secretion of insulin following meals 1 and 2 may have increased the removal of chylomicron TAG from the circulation and thus reduced its plasma concentrations. Thus, it was surprising that in the present study no differences in total plasma TAG were found between the three isoenergetic meals. In a previous comparison of non-isoenergetic meals containing 20,40 and $80 \mathrm{~g}$ fat, the plasma TAG concentration was significantly higher following the largest intake (Murphy et al. 1995).

In contrast, the plasma TAG concentration following meal 4 was significantly elevated which may reflect the lack of insulin response to this meal in comparison with the other meals. Since the chylomicron TAG concentration was not greatly elevated relative to the other meals, VLDL-TAG may have contributed significantly to the total plasma TAG concentrations following this meal. The VLDL-TAG concentration rises after a meal, reflecting competition by the chylomicron TAG for clearance by LPL (Potts et al. 1991). Higher insulin concentrations after meals 1,2 and 3 may have suppressed VLDL-TAG secretion acutely, thus minimizing the elevation in plasma TAG concentration (Gibbons, 1990). Therefore, the lack of insulin response after meal 4 may have allowed continued VLDL-TAG secretion. Furthermore, the relative elevation of plasma NEFA concentrations after meals 3 and 4 may reflect the large contribution of NEFA from the circulating chylomicron TAG, NEFA spillover of fatty acids arising from LPL action on chylomicron TAG (Coppack et al. 1990; Fielding et al. 1996). Previous studies have shown that during infusion of TAG emulsions, plasma NEFA concentrations were elevated and related to the level of LPL activity (Peterson et al. 1990; Nordenström et al. 1991). This is in agreement 
with previous studies that reported relatively elevated plasma NEFA concentrations following a meal containing $80 \mathrm{~g}$ fat compared with either pure carbohydrate or a meal containing $20 \mathrm{~g}$ fat (Griffiths et al. 1994; Murphy et al. 1995).

\section{Substrate oxidation and balance}

The lesser suppression of plasma NEFA concentrations following the higher-fat meals was accompanied by greater fat oxidation and less carbohydrate oxidation over a $5 \mathrm{~h}$ postprandial period, compared with the lower-fat meals. This is in agreement with the glucose-fatty acid cycle (Randle et al. 1963) which suggests a reciprocal relationship whereby the rate of carbohydrate oxidation is reciprocally related to the rate of fat oxidation. In the present study, the relative maintenance of elevated plasma NEFA concentrations following meals 3 and 4 may have provided a substantial contribution of fat oxidation to the RER. This was shown in the IAUC for substrate oxidation $v$. time for the four meals, fat oxidation being suppressed less after the higher-fat meals with a reciprocal suppression of carbohydrate oxidation (relative to the lowest-fat meal) during the $5 \mathrm{~h}$ postprandial period. This reciprocal relationship has previously been observed by Stubbs $e t$ al. (1993) and Verboeket-van de Venne et al. (1994). Stubbs et al. (1993) reported an elevation in fat oxidation and suppression of carbohydrate oxidation in nine men during a $2 \mathrm{~d}$ carbohydrate-depletion protocol. Equally, Verboeket-van de Venne et al. (1994) reported a significant increase in fat oxidation with increasing dietary fat content concomitant with a reduced carbohydrate intake in fourteen healthy female students following $3 \mathrm{~d}$ consumption of a low-, medium- and high-fat dietary regimen.

In contrast, this reciprocal relationship between carbohydrate and fat oxidation is not seen when the meals compared are not isoenergetic. For instance, Flatt et al. (1985) reported no differences in substrate oxidation over a $9 \mathrm{~h}$ postprandial period following the addition of $50 \mathrm{~g}$ fat to a breakfast containing $10 \mathrm{~g}$ fat. Equally, Schutz et al. (1989) reported no differences in fat oxidation during a $24 \mathrm{~h}$ period in seven young men when an additional $106 \mathrm{~g}$ fat was added to a mixed diet. Consequently, they reported a close correlation between the overall energy balance and fat balance but not the carbohydrate balance. Similar findings were reported by Abbott et al. (1988) in twenty-seven men and twentyseven women following a weight-maintenance diet. This supports the view that even over short periods of time surplus energy in the form of fat fails to promote fat oxidation and leads to a positive energy balance which closely correlates with the fat balance. It should be noted that these studies compared rates of substrate oxidation in meals with differing energy contents, and energy intakes thus increased in relation to the fat added to the meal. In the present study we compared meals which were isoenergetic with the exception of meal 4 , and which were high in energy content to ensure a positive energy balance. Energy balance was almost identical after meals 1,2 and 3, whereas there was an inverse relationship between carbohydrate and fat balance following these meals. This varied according to meal composition, with carbohydrate balance decreasing in relation to carbohydrate intake and fat balance increasing relative to intake. However, it must be pointed out that the experimental design used here is not typical of normal meals. As stated previously, the meals were deliberately of high energy content, and all meals were high in energy from fat compared with a typical breakfast. Therefore the present study should be regarded as a deliberate perturbation of the regulatory systems rather than as representative of daily life.

In summary, the present study demonstrates that energy balance is primarily regulated following isoenergetic meals, and carbohydrate and fat balances closely interrelated by 
adjusting substrate oxidation to intake. This is contrary to the view arising from the comparison of non-isoenergetic meals that rates of fat and carbohydrate oxidation are not influenced by the fat content of a meal (Flatt et al. 1985). The results emphasize the close interrelationship between carbohydrate and fat metabolism at rest following isoenergetic meals.

We thank all those who supported this work, in particular Barbara Fielding for helpful discussion, and the subjects for their co-operation and time in making this study possible. This study was supported by Mars Incorporated.

\section{REFERENCES}

Abbott, W. G. H., Howard, B. V., Christin, L., Freymond, D., Lillioja, S., Boyce, V. L., Anderson, T. E., Bogardus, C. \& Ravussin, E. (1988). Short term energy balance: relationship with protein, carbohydrate, and fat balances. American Journal of Physiology 255, E332-E337.

Astrand, P.-O. \& Ryhming, I. (1954). A nomogram for calculation of aerobic capacity (physical fitness) from pulse rate during submaximal work. Journal of Applied Physiology 7, 218-221.

Bennett, C., Reed, G. W., Peters, J. C., Abumrad, N. N., Sun, M. \& Hill, J. O. (1992). Short-term effects of dietary-fat ingestion on energy expenditure and nutrient balance. American Journal of Clinical Nutrition 55, 1071-1077.

Bratusch-Marrain, P. R., Waldhäusl, W. K., Gasic, S., Korn, A. \& Nowotny, P. (1980). Oral glucose tolerance test: effect of different glucose loads on splanchnic carbohydrate and substrate metabolism in healthy man. Metabolism 29, 289-295.

Castro, A., Scott, J. P., Grettie, D. P., Macfarlane, D. \& Bailey, R. E. (1970). Plasma insulin and glucose responses of healthy subjects to varying glucose loads during three-hour oral glucose tolerance tests. Diabetes $19,842-851$.

Coppack, S. W., Fisher, R. M., Gibbons, G. F., Humphreys, S. M., McDonough, M. J., Potts, J. L. \& Frayn, K. N. (1990). Postprandial substrate deposition in human forearm and adipose tissues in vivo. Clinical Science 79, 339-348.

Durnin, J. V. G. A. \& Womersley, J. (1974). Body fat assessed from total body density and its estimation from skinfold thickness: measurements on 481 men and women aged from 16 to 72 years. British Journal of Nutrition 32, 77-97.

Eckel, R. H. (1989). Lipoprotein lipase: a multifunctional enzyme relevant to common metabolic diseases. New England Journal of Medicine 320, 1060-1068.

Fielding, B. A., Callow, J., Owen, M., Samra, J. S., Matthews, D. R. \& Frayn, K. N. (1996). Postprandial lipemia: the origin of an early peak studied by specific dietary fatty acid intake during sequential meals. American Journal of Clinical Nutrition 63, 36-41.

Flatt, J. P., Ravussin, E., Acheson, K. J. \& Jéquier, E. (1985). Effects of dietary fat on postprandial substrate oxidation and on carbohydrate and fat balance. Journal of Clinical Investigation 76, 1019-1024.

Gibbons, G. F. (1990). Assembly and secretion of hepatic very-low-density lipoprotein. Biochemical Journal 268, 1-13.

Griffiths, A. J., Humphreys, S. M., Clark, M. L., Fielding, B. A. \& Frayn, K. N. (1994). Immediate metabolic availability of dietary fat in combination with carbohydrate. American Journal of Clinical Nutrition 59, 5359.

Lithell, H., Boberg, J., Hellsing, K., Lundqvist, G. \& Vessby, B. (1978). Lipoprotein-lipase activity in human skeletal muscle and adipose tissue in the fasting and the fed states. Atherosclerosis 30, 89-94.

McGuire, E. A. H., Helderman, J. H., Tobin, J. D., Andres, R. \& Berman, M. (1976). Effects of arterial versus venous sampling on analysis of glucose kinetics in man. Journal of Applied Physiology 41, 565-573.

Murphy, M. C., Isherwood, S. G., Sethi, S., Gould, B. J., Wright, J. W., Knapper, J. A. \& Williams, C. M. (1995). Postprandial lipid and hormone responses to meals of varying fat contents: modulatory role of lipoprotein lipase? European Journal of Clinical Nutrition 49, 579-588.

Nordenström, J., Neeser, G., Olivecrona, T. \& Wahren, J. (1991). Effect of medium- and long-chain triglyceride infusion on lipoprotein and hepatic lipase in healthy subjects. European Journal of Clinical Investigation 21, $580-585$.

Peterson, J., Bihain, B. E., Bengtsson-Olivecrona, G., Decklebaum, R. J., Carpentier, Y. A. \& Olivecrona, T. (1990). Fatty acid control of lipoprotein lipase: a link between energy metabolism and lipid transport. Proceedings of the National Academy of Sciences USA 87, 909-913.

Piers, L. S., Soares, M. J., Makan, T. \& Shetty, P. S. (1992). Thermic effect of a meal. 1. Methodology and variation in normal young adults. British Journal of Nutrition 67, 165-175. 
Potts, J. L., Fisher, R. M., Humphreys, S. M., Coppack, S. W., Gibbons, G. F. \& Frayn, K. N. (1991). Peripheral triacylglycerol extraction in the fasting and post-prandial states. Clinical Science 81, 621-626.

Randle, P. J., Garland, P. B., Hales, C. N. \& Newsholme, E. A. (1963). The glucose fatty-acid cycle. Its role in insulin sensitivity and the metabolic disturbances of diabetes mellitus. Lancet $\mathbf{i}, 785-789$.

Schutz, Y., Flatt, J. P. \& Jéquier, E. (1989). Failure of dietary fat intake to promote fat oxidation: a factor favoring the development of obesity. American Journal of Clinical Nutrition 50, 307-314.

Stubbs, R. J., Murgatroyd, P. R., Goldberg, G. R. \& Prentice, A. M. (1993). Carbohydrate balance and the regulation of day-to-day food intake in humans. American Journal of Clinical Nutrition 57, 897-903.

Verboeket-van de Venne, W. P. H. G., Westerterp, K. R. \& ten Hoor, F. (1994). Substrate utilization in man: effects of dietary fat and carbohydrate. Metabolism 43, 152-156.

Warnick, G. R. \& Albers, J. J. (1978). A comprehensive evaluation of the heparin-manganese precipitation procedure for estimating high density lipoprotein cholesterol. Journal of Lipid Research 19, 65-76. 